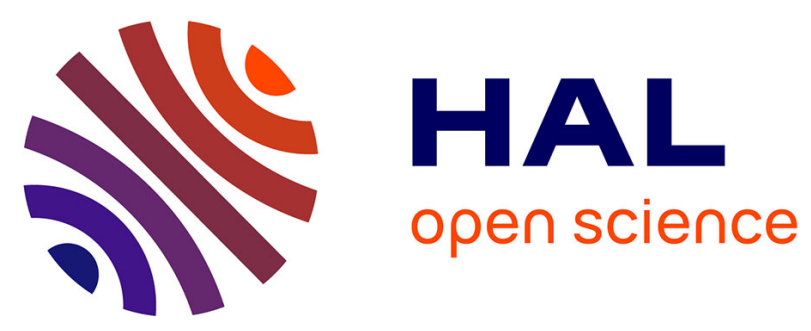

\title{
Biodiversity needs every tool in the box: use OECMs
}

Georgina G Gurney, Emily S Darling, Gabby N Ahmadia, Vera N Agostini, Natalie C Ban, Jessica Blythe, Joachim Claudet, Graham Epstein, Estradivari Estradivari, Amber Himes-Cornell, et al.

\section{- To cite this version:}

Georgina G Gurney, Emily S Darling, Gabby N Ahmadia, Vera N Agostini, Natalie C Ban, et al. Biodiversity needs every tool in the box: use OECMs. Nature, 2021, 595 (7869), pp.646-649. 10.1038/d41586-021-02041-4 . hal-03311837

\section{HAL Id: hal-03311837 https://hal.science/hal-03311837}

Submitted on 2 Aug 2021

HAL is a multi-disciplinary open access archive for the deposit and dissemination of scientific research documents, whether they are published or not. The documents may come from teaching and research institutions in France or abroad, or from public or private research centers.
L'archive ouverte pluridisciplinaire HAL, est destinée au dépôt et à la diffusion de documents scientifiques de niveau recherche, publiés ou non, émanant des établissements d'enseignement et de recherche français ou étrangers, des laboratoires publics ou privés. 


\title{
The authors
}

Georgina G. Gurney is a senior research fellow in environmental social science at the Australian Research Council Centre of Excellence for Coral Reef Studies, James Cook University, Townsville, Australia.

Emily S. Darling, Gabby N. Ahmadia,

Vera N. Agostini, Natalie C. Ban, Jessica

Blythe, Joachim Claudet, Graham Epstein,

Estradivari, Amber Himes-Cornell,

Harry D. Jonas, Derek Armitage,

Stuart J. Campbell, Courtney Cox,

Whitney R. Friedman, David Gill, Peni

Lestari, Sangeeta Mangubhai, Elizabeth

McLeod, Nyawira A. Muthiga, Josheena

Naggea, Ravaka Ranaivoson, Amelia Wenger, Irfan Yulianto, Stacy D. Jupiter.

e-mail: georgina.gurney@gmail.com

\section{Biodiversity needs every tool in the box:use OECMs}

\author{
Georgina G. Gurney, Emily S. Darling, Gabby N. Ahmadia, Vera N. Agostini, Natalie C. Ban, Jessica Blythe, Joachim Claudet, \\ Graham Epstein, Estradivari, Amber Himes-Cornell, Harry D. Jonas, Derek Armitage, Stuart J. Campbell, Courtney Cox, \\ Whitney R. Friedman, David Gill, Peni Lestari, Sangeeta Mangubhai, Elizabeth McLeod, Nyawira A. Muthiga, Josheena \\ Naggea, Ravaka Ranaivoson, Amelia Wenger, Irfan Yulianto \& Stacy D. Jupiter
}

\section{To conserve global biodiversity, countries must forge equitable alliances that support sustainability in traditional pastoral lands, fisheries-management areas, Indigenous territories and more.}

Global support is growing for the hunting areasin Mexico? All have the potential to be $30 \times 30$ movement - a goal to con- recognized using a conservation policy tool serve $30 \%$ of the planet by 2030 . In called other effective area-based conser- vation May, the G7 group of wealthy measures, or OECMs. Together with protected nations endorsed the commitment areas - from Malaysia's Taman Negara to this target that had been made by more than National Park to the Cerbère-Banyuls Marine 50 countries in January. It is likely to be the Reserve in southern France - OECMs could headline goal when parties to the Convention on help to achieve the $30 \%$ target.

Biological Diversity (CBD) meet to discuss the

Devised in 2010 and defined in 2018, the latest global conservation agreement in May OECM tool is little known outside specialist 2022 in Kunming, China. circles. Less than $1 \%$ of the world's land and

So where do the sacred forests of Estonia or freshwater environments and less than $0.1 \%$ of shipwrecks in North America's Great Lakes come marine areas are currently covered under this in? What do these share with managed fishing designation. Meanwhile, biodiversity is in free grounds in Fiji and bighorn-sheep 


\section{stem the loss. Both designations are among CONER/AIONPOIENILL}

the international policy instruments being negotiated ahead of the CBD conference.

We call on the CBD parties and the conservation community of policymakers, scientists, practitioners and donors to study and use OECMs more, alongside protected areas. This policy tool can advance equitable and effective conservation if CBD parties stay true to the convention's intent to sustain biodiversity rather than 'achieve' area-based targets. But more groundworkmustbelaid to realizeits potential.

Improvements are needed in research, policy and practice. Local managers and CBD parties need better ways to assess whether potential OECMs contribute to sustaining biodiversity, so that areas are properly designated. The conservation community needs to develop processes to ensure that OECM recognition strengthens, rather than displaces, existing local governance. And researchers need to articulate the value of OECMs to encourage policymakers to use them.

\section{Bigger toolkit}

Protected areas have expanded rapidly in the past 10 years, and now cover $15.7 \%$ of the world's land and fresh water, and $7.7 \%$ of the marine realm. Defined by the CBD as areas designated or regulated and managed for biodiversity conservation, they are an essential conservation approach. But some have failed to be equitable or effective: aligning biodiversity goals with local values, needs and governance can be difficult in some contexts 1.2 . This conflict can lead to inequities, non-compliance and poor biodiversity outcomes.

OECMs can have an important and complementary roles. The tool recognizes managed areas that sustain biodiversity, irrespective of their objective. OECM recognition can support Indigenous and local communities in managing their lands and seas - be it for hunting, fishing or other cultural practices - while conserving nature. It opens up new conservation oppor- tunities in landscapes where there is relatively light human usage, such as pastoralism with a low density of livestock. These regions make up nearly $56 \%$ of the world's lands, and contain more Key Biodiversity Areas - sites of global important to biodiversity - than do remaining large wild areas4. So, management approaches that accommodate the ways people use land- scapes and seascapes are crucial.

Some managed areas do not safeguard biodiversity. But there is a wealth of evidence suggesting that many do. For example, a study of the Peruvian Amazon found that Indigenous peoples' territories were, on average, more
Areas managed by local people can conserve nature while sustaining livelihoods and cultural practices. Recognizing them as OECMs* would allow their contribution to sustaining biodiversity to be counted.

Amazon rainforest

Almost one-third of the rainforest is Indigenous territories, of which $80 \%$ is outside protected areas.

$30 \%$ is Indigenous territories

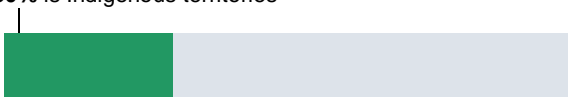

\section{Mountain farmland in Europe}

Almost one-fifth of the European Union's mountain area is highly biodiverse and depends on low-intensity farming practices.

$17 \%$ is 'High Nature Value farmland'

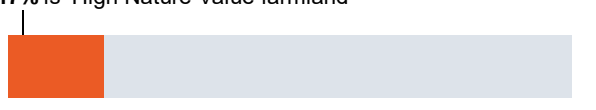

\section{Community forests in Nepa}

Almost one-quarter of the country's forests are governed by $33 \%$ of the rural population. They sustain healthy ecosystems and the well-being of inhabitants.

$\mathbf{2 3} \%$ is community forestry areas

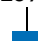

\section{Wildlife zones in Mexico}

Wildlife Management Units (UMAs) cover nearly one-fifth of the country's territory. They are governed privately or communally for sustainable uses such as hunting.

$19 \%$ is covered by UMAs

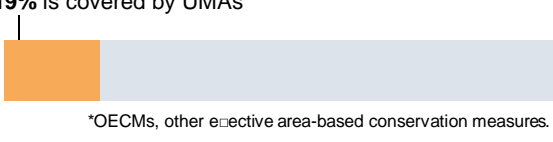

effective than state-governed protected areas at preventing deforestation ${ }_{6}$. A review of 61 areas managed under territorial-use rights in fisheries in Chile found positive effects on biodiversity; some had levels of fish biomass and biodiversity that were comparable to those in a protected area that restricts all fishing. And abandonment of agricultural management sys- tems involving low-intensity farming methods in Europe - such as traditional haymaking in Romania - has been linked repeatedly to bio- diversity loss.

Perhaps many of these could be recognized as OECMs (see 'Conservation potential'). Doing so depends on the consent of the relevant gov- erning bodies, and whether the managed area meets the CBD's definition and criteria for OECMs, including demonstrated or expected biodiversity outcomes.

\section{Equity}

OECMs can help to ensure that international conservation targets are legitimate to the many and diverse actors required to turn the tide on biodiversity loss.

Too often, the costs of conservation are felt locally while many of the benefits are shared globally - from carbon sequestration to preserving genetic resources. For instance, rainforest conservation, including a protected area, in the Ankeniheny-Zahamena Corridor in Madagascar meant that local farmers of vanilla, cloves and rice bore opportunity costs representing $27-84 \%$ of their average annual household income. The protection scheme is intended to cut 10 million tonnes of carbon dioxide emissions over 10 years.

Such inequities can occur when protected areas do not prioritize local values and needs. Although protected areas can have multiple objectives, the widely followed guidance from the International Union for Conservation of Nature (IUCN) advises that nature conserva- tion should retain priority over all other objec- tives. This can alienate people who manage areas for other reasons. Even in the instance of Indigenous Protected Areas in Australia, which have resulted in an array of social and biodiversity benefits, the IUCN definition can undermine Indigenous Australians' conceptu- alization of humans as part of nature, which underpins their governance systems. This stands in contrast to the Western world view of humans as distinct from nature - a concept that is embedded in the IUCN definition and conservation more generally $\mathrm{y}_{2.3}$.

However, OECMs need not have conservation as an objective. This means that they can be used to recognize the contributions of a myriad of actors who manage areas that sustain nature, regardless of why they do so. Indigenous peoples, for instance, manage $37 \%$ of the world's natural lands 10 for many reasons, such as maintaining rights, harvest- ing and cultural identity $y_{210,11}$. Recognition of Indigenous territories as OECMs could help to overcome current challenges of insecure rights, insufficient funding and exclusion of these communities from decision-making ${ }^{12}$. For example, Indonesia has initiated revisions to its conservation laws to accommodate coastal OECMs, which could provide opportu- nities for Indigenous and local communities to gain legal recognition of their rights to use and manage fisheries.

OECMs can thus ensure a more equitable approach to conservation decision-making. They enable the participation of those who govern areas that sustain biodiversity but who are currently not involved in decision-mak-ing. For example, fisheries-management organizations have rebuilt some fish stocks, 
contributing to biodiversity and wider tools in the global conservation system. This these areas sustain biodiversity. Another con- cern ecosystem health, yet the fisheries and con- bolsters the system's resilience to social and is that, despite the focus on equity, any servation sectors are often divided ${ }^{3}$. OECMs can biophysical shifts, including climate change ${ }^{\text {i4. }}$ attempts to influence local governance could be foster cooperation between sectors, and Redundancy in governance arrangements can perceived as a 'land grab' or 'sea grab' by encourage the participation of fisheries-man- help to mitigate risks associated with the external actors such as national governments, agement organizations in conservation current reliance on government-led pro- tected foreigners or international organizations. For decision-making.

\section{Effectiveness}

Collectively, alongside protected areas, OECMs can increase the effectiveness of the global conservation system in four key ways.

First, they support management that is tai- lored to its context $t_{14}$, and aligned with local values, way foroilandgas exploration underaformer US governance and traditional knowledge systems. presidential administration.

This fosters the local leadership, sup- port and compliance that are key to biodiver- sity benefits ${ }^{4}$, outcomes into focus. A key criterion for offi- cial For example, in Mo'orea, French Polynesia, designation is demonstrated or expected protected areas that restricted all fishing did not biodiversity outcomes, such as the restora- tion meet fishers' needs, leading to non-compliance of a crucial habitat. This is not the case for and relatively little change in the density and protected areas, where a focus on coverage has, in

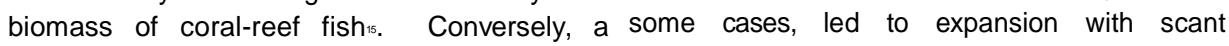
management area in Labrador, Canada, biodiversity gains.

implemented at the behest of crab fishers, maintained the fishery and increased the biomass of fish species such as Atlantic cod (Gadus morhua) and other, non-target species $^{1 .}$. This area seems likely to meet the OECM criteria.

Second, OECMs, together with protected areas, can help to ensure a well-connected conservation network in which all elements of biodiversity are represented and in which ecological processes, such as species movements, are sustained. For instance, Kenya's wildlife conservancies provide geographical bridges between protected areas for the movement of wildlife such as zebras, and have potential to be recognized as OECMs.

Third, OECMs can increase the diversity of

\section{Five steps}

Key concerns remain about the misuse of OECM recognition. CBD parties might use it to meet commitments without actually tackling biodiversity loss. For example, in 2017, Canada increased the marine area it planned to report almost sixfold, by reclassifying 51 fishery clo- sures as $\mathrm{OECMs}{ }^{\sharp}$. This decision was criticized on the grounds of insufficient evidence that al example, the establishment of some privately owned protected areas in southern Chile has been suggested to have involved coercion and intimidation of smallholder farmers.

The conservation community needs to take the following five steps to overcome these key challenges to using the OECM policy tool.

Show that they work. The 2019 IUCN Guidelines for Recognizing and Reporting OECMs provide clear criteria for identifying man- aged areas that are suitable for a full assess- ment against the CBD's definition. However, research is needed on how to meet the crucial criteria of demonstrated or expected in situ conservation of biodiversity. This is challeng- ing and resourceintensive, especially because of the variety of actors involved. Ideas based in Western science might not align with the knowledge systems of all involved.

Guidelines should build on existing approaches for evaluation, such as the IUCN Green List for Protected and Conserved Areas and the Indicators of Resilience in Socio-ecological Production Landscapes (SEPLs). They should include recent advances focused on outcomes ${ }^{18}$ and should be tailored to different types of managed area. To ensure that these are salient, credible and legitimate to those governing OECMs, they should be coproduced by groups such as rights holders, civilsociety organizations, government and industry, as well as by academics from various disciplines. This transdisciplinary approach is growing rapidly, with examples ranging from management at the national level (such as New Zealand's Sustainable Seas National Science Challenge) to the monitoring of coral reefs as social-ecological systems ${ }^{19}$.

Strengthen existing local governance. Many rights holders have raised concerns that for- mal recognition of their managed areas for conservation might infringe their rights. For example, few communities in Fiji have had their fisheries-management areas recognized under national conservation laws, because that currently requires the communities to waive their customary rights 20 .

Engaging with global conservation processes might also erode self-determination through the imposition of external world views ${ }_{2,3,12}$. Although OECMs open the door to recognizing diverse relations between humans and nature, it is crucial that the need for demonstrated or expected biodiversity outcomes does not diminish other priorities and values. OECM recognition must strengthen existing local governance, rather than displace 
or substantially alter it. This will require guidelines to be informed by principles of procedural equity and tailored to different types of managed area. Their development should draw on existing approaches such as the Australian Indigenous-led Healthy Coun- try Planning and Our Knowledge, Our Way guidelines, which have underpinned engage- ment with the national carbon sequestration scheme".

Secure funding. Funding for recognizing and reporting OECMs should be made available to ensure costs are not a barrier or burden for underresourced groups. A prominent role for OECMs in the next CBD agreement will help - this policy guides conservation investments from nations and donors.

Importantly, the diversity of managed areas that OECMs encompass can provide funding opportunities beyond conventional conservation funders, whose resources for

protected-area funding are already over- the conservation community should be guided by stretched. Conservation practitioners should the development and health sectors, which have engage private sectors that manage areas that could be recognized as OECMs, and access funding earmarked for other priorities such as health and development. For example, the Watershed Interventions for Systems Health project in Fiji, which aims to reduce waterborne diseases using nature-based solu- tions, is supported by both conservation and public-health funding.

Conservation donors and practitioners should co-design new funding strategies for OECMs with those governing these areas. This will help to ensure that local priorities are sup- ported. For example, Coast Funds, a unique conservation trust fund, was developed by concerns that there is an uneven burden of First Nations people in collaboration with proof for the OECM and protected-area tools. It conservation practitioners and the forestry could also prevent the misuse of either to meet industry to support stewardship of the Great targets based on area without actually Bear Rainforest and Haida Gwaii regions of sustaining biodiversity.

British Columbia, Canada.

Agree on metrics. The record of progress towards the CBD's area-based target, the World Database on Protected Areas, assumes that all reported protected areas have biodiversity conservation as a main objective. But some CBD parties report areas that have other primary objectives, such as sustainable harvesting $_{20}$. This leads to inaccurate accounting at the global level, and to misunderstanding of management actually occurring on the ground. Canada, among others, is developing legislation that demarcates protected areas and OECMs. Butitis not clear whether all CBD parties will do the same.

Policymakers need to agree on targets that are based on outcomes - not just coverage - for both OECMs and protected areas. These might include, for example, changes in the populations of multiple species relative to a reference point. In constructing these targets,
United Nations Sustainable Development Goal 3. Jonas, H. D., Barbuto, V., Jonas, H. C., Kothari, A. \&

(2019). people living in multidimensional, regionally- 5. Donald, P. F. et al. Conserv. Lett. 12, e12659 (2019). defined poverty by 2030. A com- mon currency 6. Schleicher, J., Peres, C. A., Amano, T., Llactayo, W. \& of outcomes could alleviate

"Ideas based in Western science might notalign with the knowledge systems of all involved." Leader-Williams, N. Sci. Rep. 7, 11318(2017).

7. Gelcich, S., Martínez-Harms, M. J., Tapia-Lewin, S. Vasquez-Lavin, F. \& Ruano-Chamorro, C. Conserv. Lett. 12 e12637 (2019).

8. Lomba, A. et al. Front. Ecol. Environ. 18, 36-42 (2020).

9. Poudyal, M. et al. PeerJ6,e5106 (2018).

10. Garnett, S. T. et al. Nature Sustain. 1, 369-374 (2018).

11. Ansell, J. et al. Int. J. Wildland Fire 29, 371-385 (2019)

12. Corson, C. et al. Conserv. Soc. 12, 190-202 (2014).

13. Hilborn, R. Nature 535, 224-226 (2016).

14. Carlisle, K. \& Gruby, R. L. Policy Stud. J. 47, 927-952 (2019).

15. Thiault, L. et al. Ecosphere 10, e02576 (2019).

16. Kincaid, K. \& Rose, G. Can. J Fish. Aqua. Sci. 74, 1490-1502 (2017).

17. Lemieux, C. J. \& Gray, P. A. J. Environ. Stud. Sci. 10 483-491 (2020).

18. Geldmann, J. et al. Conserv. Lett. https://doi.org/10.1111/ conl.12792 (2021)

19. Gurney, G. G. et al. Biol. Conserv. 240, 108298 (2019).

Include OECMs in other environmental

agreements. Addressing the interrelated global challenges of biodiversity loss, climate change and sustainability requires the coordination of policy across sectors. Right now, OECMs appear only in CBD policy. But they could contribute to the mandates of other intergovernmental initiatives. Policymakers should include OECMs alongside protected areas in international agreements such as the Sustainable Development Goals, new global climate agreements being negotiated under the UN convention on climate, and the emerg- ing UN treaty on marine biodiversity in areas beyond national jurisdiction.

New targets negotiated at the upcoming CBD meeting will set the global conservation agenda over the next decade. If the steps we outline here are implemented, OECMs could be central to the transformations needed for a sustainable future for the planet. (O2021 Springer Nature Li mited All rights reserved 